\title{
Untargeted metabolomics in doping control: detection of new markers of testosterone misuse by ultra-high performance liquid chromatography coupled to high resolution mass spectrometry
}

Montse Raro ${ }^{\mathrm{a}}$, María Ibáñez ${ }^{\mathrm{a}}$, Rubén Gil ${ }^{\mathrm{a}}$, Andreu Fabregat ${ }^{\mathrm{b}}$, Eva Tudela $^{\mathrm{c}}$, Koen Deventer $^{\mathrm{c}}$, Rosa $^{\mathrm{a}}$ Ventura $^{\mathrm{b}, \mathrm{d}}$, Jordi Segura ${ }^{\mathrm{b}, \mathrm{d}}$, Josep Marcos ${ }^{\mathrm{b}, \mathrm{d}}$, Aristotelis Kotronoulas ${ }^{\mathrm{b}, \mathrm{e}}$, Jesús Joglar ${ }^{\mathrm{e}}$, Magi Farré ${ }^{\mathrm{f}}$, Sheng Yang ${ }^{\mathrm{g}}$, Yanyi Xing ${ }^{\mathrm{g}}$, Peter Van Eenoo, Elena Pitarch ${ }^{\mathrm{a}}$, Félix Hernández ${ }^{\mathrm{a}}$, Juan Vicente Sancho $^{\mathrm{a}}$, Óscar J. Pozo ${ }^{\mathrm{b}^{*}}$

${ }^{a}$ Research Institute for Pesticide and Water, University Jaume I, Av. Sos Baynat S/N, 12071 Castellón, Spain

${ }^{\mathrm{b}}$ Bioanalysis Research Group. IMIM, Hospital del Mar, Dr. Aiguader 88, 08003 Barcelona, Spain

${ }^{\mathrm{c}}$ DoCoLab, Ghent University, Technologiepark 30, 9052, Zwijnaarde, Belgium

${ }^{\mathrm{d}}$ Department of Experimental and Health Sciences, Universitat Pompeu Fabra, Doctor Aiguader 88, o8ooz Barcelona, Spain

${ }^{\mathrm{e}}$ Department of Biological Chemistry and Molecular Modelling, Institute of Advanced Chemistry of Catalonia, Spanish Council for Scientific Research (IQAC-CSIC), Jordi Girona 18-26, o8034 Barcelona, Spain

${ }^{\mathrm{f}}$ Human Pharmacology and Neurosciences Research Group, IMIM, Clinical Pharmacology Unit, Hospital Universitari Germnans Trias I Pujol-IGTP and Universitat Autònoma de Barcelona, Doctor Aiguader 88, o8003 Barcelona, Spain

${ }^{\mathrm{g}}$ National Anti-Doping Laboratory China Anti-Doping Agency, 1, An Ding Road, Beijing, 10oo29, China

KEYWORDS: UHPLC-(Q)TOF MS, Orbitrap, Testosterone, doping, metabolomics, multivariate analysis

\begin{abstract}
The use of untargeted metabolomics for the discovery of markers is a promising and virtually unexplored tool in the doping control field. Hybrid quadrupole time-of-flight (QTOF) and hybrid quadrupole Orbitrap (Q Exactive) mass spectrometers, coupled to ultra-high pressure liquid chromatography are excellent tools for this purpose. In the present work, QTOF and Q Exactive have been used to look for markers for testosterone cypionate misuse by means of untargeted metabolomics. Two different groups of urine samples were analyzed; collected before and after the intramuscular administration of testosterone cypionate. In order to avoid analyte losses in the sample treatment, samples were just two-fold diluted with water, and directly injected into the chromatographic system. Samples were analyzed in both positive and negative ionization modes. Data from both systems were treated under untargeted metabolomic strategies using XCMS application and multivariate analysis. Results from the two mass spectrometers differed in the number of detected features, but both led to the same potential marker for the particular testosterone ester misuse. The in-depth study of the MS and MS/MS behavior of this marker allowed for the establishment of 1-cyclopentenoylglycine as feasible structure. The putative structure was confirmed by comparison with synthesized material. This potential marker seems to come from the metabolism of the cypionic acid release after hydrolysis of the administered ester. Its suitability for doping control has been evaluated.
\end{abstract}

\section{INTRODUCTION}

Metabolomics is one of the most useful approaches for the discovery of new metabolites or markers. It consists of the comprehensive measurement of the low-molecular weight metabolites of a cell, tissue or body fluid, resulting from metabolic processes in organisms ${ }^{1}$. Large number of data is commonly obtained from analytical platforms based on mass spectrometry (MS) and Nuclear Magnetic Resonance (NMR). The selection of the instrumentation is an important issue since it is a key factor regarding the number of peaks detected and their sensitivity/specificity. Due to their high resolution, mass accuracy and fullspectrum acquisition capabilities, high resolution (HR) mass analyzers such as Orbitrap, TOF or hybrids analyzers like quadrupole-time of flight (QTOF) and quadrupole Orbitrap (Q Orbitrap) are adequate to develop metabolic profiling methods in complex biological matrices such as urine $^{2-4}$. Profiling at metabolite levels or an individual's 
response to stimuli, environment or drug treatment are well described ${ }^{5}$; as well as other applications in food sciences $^{3,6}$, plant metabolomics ${ }^{7}$ and clinical research ${ }^{8,9}$ among others. However, its implementation in other fields such as doping control is rather limited.

The potential usefulness of metabolomics for doping control purposes is described on literature ${ }^{10-12,}$ where it is illustrated that "omics" methods may be ideal platforms for the discovery of markers of the abuse of some prohibited substances or methods for which the direct detection presents difficulties. This is the case of endogenous anabolic androgenic steroids (EAAS) like testosterone (T).

EAAS are responsible for the largest number of adverse analytical findings reported by doping control laboratories $^{13}$. EAAS are naturally present in humans, thus, the detection of the misuse of this group of compounds a challenging task. Ratio between urinary $\mathrm{T}$ and epitestosterone (E), both excreted as glucuronides (T/E), was firstly used to distinguish between natural and administrated testosterone by Donike et al. in $1983^{14}$. This ratio provided a solution to screen for $\mathrm{T}$ misuse until it was found that people with a common deletion polymorphism in the UGT2B17 gene excreted low concentration of $\mathrm{T}$, thus generating abnormally low $\mathrm{T} / \mathrm{E}$ ratios even after testosterone administration ${ }^{15,16}$. Nowadays, the current strategy for the screening of EAAS is based on the quantification in every urine sample of the so-called steroid profile, i.e. seven markers related with $\mathrm{T}$, and its inclusion in the Athlete Biological Passport ${ }^{17}$ (ABP). The discovery of alternative markers which might complement the steroid profile is currently an active research topic in the doping control field. Several alternative $\mathrm{T}$ metabolites have been proposed for this purpose ${ }^{18,19}$. The application of target metabolomic approaches has been described as a useful tool for the selection of new markers ${ }^{20,21}$. Open detection methods, i.e. scan acquisition of the whole $m / z$ range using high resolution mass spectrometry have been used for the differentiation of the metabolic profiles before and after testosterone administration ${ }^{12}$. However, the untargeted results were filtered by the expected $\mathrm{m} / \mathrm{z}$ of $\mathrm{T}$ metabolites and only the expected ones (metabolites coming from known pathways such as hydroxylation, reduction, oxidation and conjugation either with glucuronic acid or with sulfate) were considered for the ulterior statistical analysis. Although untargeted metabolomics has been used for the detection of pathways altered after the administration of different doping agents ${ }^{22}$, its potential for the detection of alternative markers remains virtually unexplored in this field.

The goal of the present study is to evaluate the potential of untargeted metabolomics in the doping control field, analyzing the differences and similarities between two systems: UHPLC-QTOF and UHPLC-QOrbitrap. By means of a metabolomic approach and using these powerful analytical techniques, markers of $\mathrm{T}$ misuse after $\mathrm{T}$ cypionate administration were investigated. The experimental design aimed to detect those markers which can be detectable even several days after administration irrespective on the basal T/E values.

\section{MATERIALS AND METHODS}

\subsection{Reagents and chemicals}

For QTOF analysis, HPLC-grade water was obtained by purifying demineralised water in a Milli-Q plus system from Millipore (Bedford, MA, USA). HPLC-grade methanol $(\mathrm{MeOH})$, residue analysis grade acetone, sodium hydroxide (>99\%) and formic acid (98-100\%) were acquired from Scharlab (Barcelona, Spain). Leucine-Enkephalin, used as the lock mass, was purchased from Sigma Aldrich (St. Louis, MO, USA).

In case of Q Orbitrap analysis, LC-MS grade methanol and LC-MS grade water were purchased from Biosolve (Valkenswaard, Netherlands). Formic acid Optima ${ }^{\circledR}$ LC/MS was purchased from Fischer Scientific (Loughborough, UK). Exactive Calibration Kit solutions employed were purchased from (Sigma-Aldrich, St. Louis, MO, USA and ABCR GmbH \& Co. KG, Karlsruhe, Germany).

For the synthesis of the 1- cyclopentenoylglycine (1CPG), 1-cyclopetenecarboxilic acid, glycine, benzyl chloroformate, triethylamine and dimethyl sulfoxide (DMSO) were purchased from Sigma-Aldrich Química S.A. (Madrid, Spain) and trifluoroacetic acid (TFA) was purchased from Carlo Erba Reagents (Barcelona, Spain). Finally, deuterated methanol ( $\left.\mathrm{CD}_{3} \mathrm{OD}\right)$ used in the NMR experiments was purchased from Euriso Top (Saint-Aubin, France).

\subsection{Instrumentation}

2.2.1 Xevo G2 QTOF

Acquity ultra-performance liquid chromatography system (Waters, Milford, MA, USA) was interfaced to a Xevo G2 QTOF mass spectrometer (Waters Micromass, Manchester, UK) using an orthogonal Z-spray electrospray (ESI) interface. The chromatographic separation was performed using an Acquity UPLC BEH C18 column $(1.7 \mu \mathrm{m}$, $2.1 \times 100 \mathrm{~mm}$ ) from Waters, using a flow rate of 0.3 $\mathrm{mL} / \mathrm{min}$. The mobile phases used were (A) $\mathrm{H}_{2} \mathrm{O}$ and (B) $\mathrm{MeOH}$, both with $0.01 \%(\mathrm{v} / \mathrm{v}) \mathrm{HCOOH}$. The percentage of $\mathrm{MeOH}$ was linearly increased as follows: $1 \mathrm{~min}, 2 \%$; $3 \mathrm{~min}$, 15\%; $6 \mathrm{~min}, 50 \%$; $9 \mathrm{~min}, 95 \%$; $10 \mathrm{~min}, 95 \%$; $10.01 \mathrm{~min}, 2 \%$ and $12 \mathrm{~min}, 2 \%$. The total run time was $12 \mathrm{~min}$. The injection volume was $20 \mu \mathrm{L}$. Nitrogen (Praxair, Valencia, Spain) was used as both drying and nebulizig gas. The desolvation gas flow rate was set at $1000 \mathrm{~L} / \mathrm{h}$. The resolution of the TOF mass spectrometer was $\sim 20,000$ at full width half maximum (FWHM) at $\mathrm{m} / \mathrm{z} 556$. MS data were acquired over a $\mathrm{m} / \mathrm{z}$ range of 50-1000 with a scan time of 0.4 s. Capillary voltages of $0.7 \mathrm{kV}$ and $2.5 \mathrm{kV}$ were used in positive and negative ionization modes, respectively. A cone voltage of $20 \mathrm{~V}$ was applied. Argon was used as collision gas (99.995\%, Praxair). The interface temperature was set to $55^{\circ}{ }^{\circ} \mathrm{C}$ and the source temperature to $130{ }^{\circ} \mathrm{C}$. The column temperature was set to $40{ }^{\circ} \mathrm{C}$ and the autosampler to $5^{\circ} \mathrm{C}$. The same cone voltage and collision energy ramp was used for additional tandem MS (MS/MS) experiments.

Calibration of the mass-axis and automated accurate mass measurement are described in supporting information (Section $\mathrm{S} 1$ ). 


\subsubsection{Q-Exactive Orbitrap}

The liquid chromatographic system was an Accela LC (Thermo Scientific, Bremen, Germany) equipped with degasser, Accela 1250 pump, autosampler at $7^{\circ} \mathrm{C}$ and a heated column compartment at $40^{\circ} \mathrm{C}$. The same column, injection volume, chromatographic conditions, mobile phases, flow rate and gradient employed in the QTOF system, were used in this instrument. The LC effluent was pumped to a Q-Exactive benchtop Orbitrap based mass spectrometer (Thermo Scientific, Bremen, Germany) operating in the positive/negative polarity switching mode and equipped with an electrospray (ESI) source. Nitrogen sheath gas flow rate and auxiliary gas were set at 50 and 20 (arbitrary units), respectively. The S-lens RF level was set at 100 (arbitrary units). The capillary temperature was $250^{\circ} \mathrm{C}$ and the spray voltage $4 \mathrm{kV}$ in both ion modes. The instrument operated in full spectrum acquisition from $\mathrm{m} / \mathrm{z} 50$ to 1000 . The resolution was 35,000 (FWHM at $\mathrm{m} / \mathrm{z}$ 200) with a scan time of $0.45 \mathrm{~s}$ in polarity switching mode. The automatic gain control (AGC) was $10^{6}$. Data were acquired in centroid mode. The Q Orbitrap performance in both positive and negative ionization modes was daily evaluated daily and external calibration was daily done with Calibration Kit solutions.

\subsection{Administration study samples}

Eight healthy male volunteers were included in two T excretion studies (one performed in Spain and the other one in China). Four volunteers with T/E values between 1 and 3 (coming from the first study) and four volunteers with T/E values below 0.3 (coming from the second one) were selected. Four basal urine samples (first morning urine) were collected, three of them during the three consecutive days before the administration $(-72 \mathrm{~h},-48 \mathrm{~h}$ and $24 \mathrm{~h}$ ) and, the other one, the day of the administration (o $\mathrm{h}$ ). After the administration of a single dose of $100 \mathrm{mg}$ of testosterone intramuscularly injected (Testex prolongatum $^{\circledR}, 1$ vial of $2 \mathrm{~mL}$ containing $100 \mathrm{mg}$ of testosterone cypionate, Desma Laboratorio Farmaceutico, Madrid, Spain), several samples were collected up to 15 days after administration. Samples were stored at $-20{ }^{\circ} \mathrm{C}$ until the analysis.

Subjects signed an informed consent before participation. Both protocols were approved by the local Research Ethics Committees and authorized by the state authorities. Both studies were conducted in accordance with the Declaration of Helsinki and state laws concerning clinical trials. Treatment was well tolerated by the subjects and no serious adverse events were observed.

For the metabolomic study, urine samples before (4 samples) and after administration (7 samples collected on days 1, 2, 3, 4, 5, 7 and 9) were considered for the analysis. A total of 32 pre-administration samples (4 per 8 volunteers) formed the group Control and 56 postadministration samples (7 per 8 volunteers) formed the group Treated.

\subsection{General strategy}

The general 4-steps workflow followed during this work is described below and is summarized in Figure S1 (supporting information).

\subsubsection{Sample treatment and injection}

$500 \mu \mathrm{L}$ of HPLC-grade water were added to the same volume of urine samples. The diluted extracts were directly injected into the UHPLC-QTOF and Q-Exactive MS systems in both positive and negative ionization modes. Samples were randomly injected in order to avoid that the results might be affected by the instrumental drift. Quality control (QC) samples were prepared by a pool of all the extracts in order to be a good representation of all the samples. Firstly, 10 QCs were injected in order to stabilize the chromatographic system and then an additional QC sample was injected every 10 samples in order to check the stability and the robustness of the measurements.

Gradient elution was optimized in the QTOF for both positive and negative ionization mode injections, focusing on a better separation of the visible peaks in the Base Peak Ion (BPI) chromatograms.

\subsubsection{Data pre-processing and multivariate analysis}

The raw data acquired by the UHPLC-QTOF MS with the MassLynx operating software (version 4.1, Waters) were converted to Common Data Format (CDF) files using the Databridge application (from MassLynx).

Raw data acquired by the UHPLC-QOrbitrap MS with Xcalibur 2.2 were initially separated into positive and negative files and then converted into CDF files using a conversion option provided within the Xcalibur software.

The CDF data from both instruments were preprocessed in the same way using the XCMS free software $^{23}$. First, a peak picking centWave method was used to locate mass traces and then, continuous wavelet transform (CWT) was applied to find chromatographic peaks (peak width $=5-20 \mathrm{~s}, \mathrm{~S} / \mathrm{N}$ threshold $=10, \mathrm{ppm}=15)$. Then, a density grouping method was applied to align the retention times of peaks with the same exact mass in all samples. For this purpose, a cluster of "well behaved peaks", present in all samples with stable intensities, were used to correct the rest from an initial band width of $5 \mathrm{~s}$ to $1 \mathrm{~s}$, after 4 iterations. The peak list provided by XCMS was normalized using loess normalization method ${ }^{24}$ and then imported into the EZinfo software (Umetrics, Umea, Sweden) for multivariate analysis. Principal Component Analysis (PCA), Partial Least Squares-Discriminant Analysis (PLS-DA) and Orthogonal Partial Least SquaresDiscriminant Analysis (OPLS-DA) were evaluated after unit variance (UV) scaling to look for the potential markers. In the OPLS-DA, samples belonging to Control and Treated classes were used for comparison.

\subsubsection{Marker selection}

The S-Plots generated by OPLS-DA, were studied in order to obtain a list of candidates. Points located at the top right or at the bottom left were studied in all cases, corresponding to the best markers which increase or decrease, respectively, after $\mathrm{T}$ administration. Feasibility of the can- 
didates was evaluated based on their Variable Trend Plots, adequate abundances and peak shapes.

\subsubsection{Marker identification}

In order to elucidate the structure of the potential marker, both MS and MS/MS spectra were studied. The molecular formula of the marker was obtained by the use of the accurate mass measurements of the precursor ion. This information together with that obtained after collision-induced dissociation at different collision energies was used for establishing a feasible structure for the marker. Confirmation of the hypothesis was performed after synthesis of the proposed structure.

\subsection{Synthesis of 1-cyclopentenoylglycine (1-CPG)}

For the synthesis of 1-CPG, $30 \mathrm{mg}$ of 1cyclopentenecarboxylic acid were dissolved in $0.5 \mathrm{~mL}$ of acetonitrile and $22 \mu \mathrm{L}$ of triethylamine were added. The solution was cooled to $4^{\circ} \mathrm{C}$ and $50 \mu \mathrm{L}$ of benzyl chloroformate were added. The reaction was left to proceed for $24 \mathrm{~h}$ under vigorous stirring at room temperature. After that, the solvents were removed under vacuum and the residue was dissolved in $0.5 \mathrm{~mL}$ of DMSO that contained $40 \mu \mathrm{L}$ of triethylamine. Then, $30 \mathrm{mg}$ of glycine dissolved in $0.5 \mathrm{~mL}$ of water were added and the reaction was left to proceed for $24 \mathrm{~h}$ at room temperature. The HPLC purification of the product is detailed in the supporting information (section S2). Finally, after solvent removal, $16 \mathrm{mg}$ of product as white solid were obtained.

The characterization of the final product was performed by NMR on a Mercury $400 \mathrm{MHz}$ spectrometer equipped with OneNMR ProTune system probe. The NMR experiments were performed in deuterated methanol $\left(\mathrm{CD}_{3} \mathrm{OD}\right)$ and chemical shifts are reported in $\mathrm{ppm}$ relative to the residual non deuterated methanol $(\delta=3.31$ ppm for ${ }^{1} \mathrm{H}-\mathrm{NMR}$ and $\delta=49 \mathrm{ppm}$ for $\left.{ }^{13} \mathrm{C}-\mathrm{NMR}\right) .{ }^{1} \mathrm{H}$ NMR $\left(400 \mathrm{MHz}, \mathrm{CD}_{3} \mathrm{OD}\right) \delta=6.62\left(\mathrm{~m},{ }^{1} \mathrm{H}\right), 3.95\left(\mathrm{~s},{ }^{2} \mathrm{H}\right), 2.58$ (ddq, $\mathrm{J}=10.1,4.5,2.4 \mathrm{~Hz},{ }^{2} \mathrm{H}$ ), 2.51 (ddq, $\mathrm{J}=10.4,5.1,2.6$ $\left.\mathrm{Hz},{ }^{2} \mathrm{H}\right)$, $2.00\left(\mathrm{p}, \mathrm{J}=7.6 \mathrm{~Hz},{ }^{2} \mathrm{H}\right) .{ }^{13} \mathrm{C} \mathrm{NMR}(101 \mathrm{MHz}$, $\left.\mathrm{CD}_{3} \mathrm{OD}\right) \delta=175.68,169.34,139.80,41.34,31.87,33.66,23.87$.

\section{6. $1-\mathrm{CPG}$ and $\mathrm{T} / \mathrm{E}$ evaluation}

In order to show the potential applicability of 1-CPG for doping control purposes, it was qualitatively determined in all samples collected from two volunteers, with basal $\mathrm{T} / \mathrm{E}$ values of 2.9 and 0.15 respectively. The analysis was based on a two fold dilution of the sample with acetic acid $1 \mathrm{M}$ and subsequent determination by LC-MS/MS with triple quadrupole analyzer using the transition $170 \rightarrow 95$. All the details about this determination can be found in the supporting information (section $\mathrm{S}_{3}$ ).

For comparison purposes, the common marker T/E was determined in the same samples by gas chromatography coupled to mass spectrometry (GC-MS) as described elsewhere $^{25}$.

\section{RESULTS AND DISCUSSION}

3.1. Sample treatment, data pre-processing and multivariate analysis
A "Dilute-and-shoot" strategy was applied to the urine samples in order to minimize losses during sample preparation and because it is a low time-consuming ${ }^{26}$.

Samples were divided into two groups. The first one (Control) contained all samples collected before administration and the second one (Treated) those collected after administration (from day 1 to day 9). In order to extract those markers which allow for the detection of $\mathrm{T}$ misuse for long periods irrespective of the basal T/E values, neither the time after administration nor the basal $\mathrm{T} / \mathrm{E}$ value were considered into the data analysis.

The obtained data were pre-processed by XCMS for automatic peak detection and retention time alignment, generating tables of possible markers for each sample given by $m / z$ and retention time in seconds with the format MxxxTxxx (where Mxxx stands for $m / z$ and Txxx for retention time). In the QTOF analysis, 9889 and 11910 unique peaks were found in positive and negative ionization modes, respectively, whereas these values decreased when using Q Orbitrap to 7451 and 5528, respectively. These features included isotopes, adducts, and/or insource fragments. The differences might be explained either by a potentially higher sensitivity of the QTOF or by the possible generation of a larger number of adducts/in-source fragments in the ESI interface of this analyzer.

XCMS data were first normalized to take into account the drift of the instrument as well as differences in urine concentration due to differences in the excreted volume. After loess normalization, intensities were more stable in the samples, in both positive and negative ionization modes, as it can be seen in Figure S2, supporting information. These normalized data were then analyzed by PCA to have a non-supervised visualization of the results (Figure $\mathrm{S}_{3}$, supporting information).

The use of QCs in non-targeted metabolomics analysis can be considered equivalent to the use of standards in target analysis, and their importance is described in the literature $^{27,28}$. The PCA analysis showed that QCs were just in the middle of the plot, which implies that they could be regarded as representative of all the samples. Additionally, discrimination between samples before and after $\mathrm{T}$ cypionate administration was clearly observed in PCA for QTOF data (Figure S3, supporting information).

The next step was the application of a PLS-DA, a supervised method that takes into account class information. Both instruments showed good discrimination of the groups (before and after $\mathrm{T}$ administration) irrespective of the ionization mode used (Figure $\mathrm{S}_{4}$, supporting information).

Finally, an OPLS-DA was applied in order to enhance the differences between selected classes (Control and Treated). This algorithm is a powerful tool for the analysis of qualitative data structures. It consists in an extension of the previous PLS regression method which integrates an orthogonal signal correction filter ${ }^{29}$. In the generated S-plots (Figure 1 for Q Orbitrap and Figure $\mathrm{S}_{5}$ of supporting information for QTOF), points located at the top right 
square correspond to the features that increase after $\mathrm{T}$ administration whereas points at the bottom left square represent those that decrease after $\mathrm{T}$ administration.

\subsection{Selection of the marker}

The list of the top five features for QTOF and Q Orbitrap of each ionization mode is shown in Table 1.

The variable trend plots of all the candidates that increased and decreased after $\mathrm{T}$ administration were evaluated. Variable trend plots from Q Orbitrap candidates $\mathrm{M}_{170} \mathrm{~T}_{30}{ }_{5}$ and M333T230 are shown in Figure $\mathrm{S}_{5}$ (supporting information), where it can be observed the different behavior of two candidates with a $\mathrm{p}$ (corr) value of 0.60247 and 0.36836, respectively. Features with the highest $\mathrm{p}$ (corr) and with suitable variable trend plot were selected as candidates.

Due to their low $\mathrm{p}$ (corr), none of the features that decreased after $\mathrm{T}$ administration was found to be a relevant candidate (Table 1). Regarding the features which increased after $\mathrm{T}$ cypionate administration, the use of $\mathrm{Q}$ Orbitrap revealed the presence of only one marker in each ionization mode whereas the use of QTOF was able to detect two and four markers in positive and negative modes, respectively. The two potential markers obtained by QTOF in positive ionization mode shared the same retention time (295 s) suggesting that both features were generated by the same compound. In negative ionization, the use of QTOF allowed for the detection of additional features with $\mathrm{p}$ (corr) values higher than 0.5 (Table 1).

These results illustrate that the larger number of features found by QTOF compared to Q Orbitrap seems to be related to both, a larger number of detected compounds and higher in-source fragmentation/adduct formation.

Remarkably, the compound eluting at around $300 \mathrm{~s}$ was found by both instruments illustrating the suitability of both platforms for the detection of untargeted markers. This fact, together with the elevated $\mathrm{p}$ (corr), the adequate peak shape and the suitable variable trend plot advised for the selection of this compound as suitable marker. This marker was detected in both ionization modes with $\mathrm{m} / \mathrm{z} 170$ and $\mathrm{m} / \mathrm{z} 168$ in positive and negative modes, respectively. In the case of QTOF, the feature M95T295 was also observed. This feature could be explained as an insource fragment generated from M170T295, considering the retention time match. This feature was not observed in the data obtained with the Q Orbitrap, most likely due to the different source designs.

\subsection{Structural elucidation of the potential marker}

The first step for the structural elucidation was to establish the molecular formula of the marker. For this purpose, the exact masses of both protonated $[\mathrm{M}+\mathrm{H}]^{+}$and deprotonated $[\mathrm{M}-\mathrm{H}]^{-}$ions were extracted from the information processed by XCMS (Table 2 ). From the positive ionization data, an accurate mass of $\mathrm{m} / \mathrm{z} 170.0818$ was obtained for the marker, and $\mathrm{C}_{8} \mathrm{H}_{12} \mathrm{NO}_{3}$ was established as possible elemental composition of $[\mathrm{M}+\mathrm{H}]^{+}$(mass error o ppm). In negative mode, this marker showed an $\mathrm{m} / \mathrm{z}$
168.0657 corresponding to $\mathrm{C}_{8} \mathrm{H}_{10} \mathrm{NO}_{3}$ (mass error of $\mathbf{- 2 . 4}$ $\mathrm{ppm})$. All taken together allowed for the establishment of $\mathrm{C}_{8} \mathrm{H}_{11} \mathrm{NO}_{3}$ as elemental composition for the marker. The ionization in both modes as $[\mathrm{M}+\mathrm{H}]^{+}$and $[\mathrm{M}-\mathrm{H}]^{-}$suggested the simultaneous presence of an acidic and a basic moiety in the molecule.

As a second step for structural elucidation, MS/MS experiments were carried out at different collision energies in positive and negative ionization modes (Table 2). In positive, a predominant product ion at $\mathrm{m} / \mathrm{z} 95.0493$ was observed. This ion corresponded with the feature M95T295 observed in the QTOF, thus confirming that it was produced by in-source fragmentation. The elemental composition of this ion was $\mathrm{C}_{6} \mathrm{H}_{7} \mathrm{O}$ (mass error $-4.2 \mathrm{ppm}$ ) and therefore, it was formed after the neutral loss of $\mathrm{C}_{2} \mathrm{H}_{5} \mathrm{NO}_{2}$. This formula matches with the amino acid glycine suggesting that the marker is a conjugate with glycine. This fact was in agreement with the ionization observed in both modes. The formula of the ion at $\mathrm{m} / \mathrm{z}$ $95.0498\left(\mathrm{C}_{6} \mathrm{H}_{7} \mathrm{O}\right)$ had a double bond equivalent of 3.5 which is indicative of the presence of 3 unsaturations. When increasing the collision energy, an extra loss of $\mathrm{CO}$ was observed $\left(\mathrm{m} / \mathrm{z} 67.0543, \mathrm{C}_{5} \mathrm{H}_{7}\right.$ mass error $\left.-4.5 \mathrm{ppm}\right)$ suggesting the presence of a carbonyl group close to the glycine. The resultant ion $\left(\mathrm{C}_{5} \mathrm{H}_{7}\right)$ had a double bond equivalent of 2.5 indicative of the presence of either two double bonds or a double bond and a ring. In the last case, a cyclopentene moiety was the most feasible structure for the formula $\mathrm{C}_{5} \mathrm{H}_{7}$ owing to the stability of the five-member ring structure.

In negative ionization mode, the product ion spectrum was dominated by a loss of $\mathrm{CO}_{2}\left(\mathrm{~m} / \mathrm{z} 124.0758, \mathrm{C}_{7} \mathrm{H}_{10} \mathrm{NO}\right.$ mass error $-3.2 \mathrm{ppm}$ ) (Table 2 ). These results were indicative of a carboxylic acid moiety.

Based on this information, 1-CPG was postulated as feasible structure for the selected marker.

\subsection{Confirmation of the proposed structure}

The confirmation of the proposed structure was made by comparison of the product ion spectra of the selected marker with the synthesized 1-CPG. The results are shown in Figure 2. The product ion scan spectra in both ionization modes and the retention times were identical. These results allowed for the ultimate confirmation of the identity of the marker.

3.5. Significance of the marker and potential application

The pathway behind the occurrence of 1-CPG in urine after $\mathrm{T}$ cypionate injection was studied and a proposal for the formation of this marker is shown in Figure 3. As a first step, the hydrolysis of $\mathrm{T}$ cypionate releases free $\mathrm{T}$ and cypionic acid. Similar to fatty acids, cypionic acid might undergo $\beta$-oxidation as main metabolic pathway ${ }^{30}$. After activation, this pathway involves two main processes: firstly the formation of a conjugated double bond and secondly the oxidative breakdown of this double bond releasing acetyl-CoA. While linear fatty acids suffer sequential $\beta$-oxidation reactions until their total degradation, the second $\beta$-oxidation for cypionic acid is unable to produce acetyl-CoA due to its cyclic nature. Therefore the 
degradation process is stopped after the formation of the second double bond. At this point, the 1-cyclopentenoyl$\mathrm{CoA}$ formed is conjugated with glycine. Conjugation with glycine is a common metabolic pathway preceding the urinary excretion of several acids like benzoic acid, 3indoleacrylic acid or acetylsalicylic acid ${ }^{31,32}$.

The potential usefulness of 1-CPG for $\mathrm{T}$ cypionate screening misuse was also evaluated and compared with the common marker $\mathrm{T} / \mathrm{E}$ (Figure 4).

The screening of $\mathrm{T}$ misuse by the detection of an exogenous compound has obvious advantages since the mere presence of the marker is sufficient to detect a suspicious sample. A small peak was found in every basal sample at the expected retention time (Figure $S_{7}$ ). That opens the possibility for $1-\mathrm{CPG}$ to be endogenous. Further research is needed to confirm the endogenous nature of the marker.

Results showed around 50-fold increase of 1-CPG after T administration (Figures 4 and $\mathrm{S}_{2}$ ) which was substantially higher than the observed for T/E ( 7 fold). Since the metabolic pathway involved in the excretion of 1-CPG does not contain any glucuronidation step, the occurrence of this marker is irrespective of the polymorphism in the $\mathrm{UGT}_{2} \mathrm{~B}_{17}$ gene affecting the T/E excretion. Therefore, similar differences were observed in both volunteers.

Whereas T/E was back to basal levels 10-11 days after administration, $1-C P G$ responses were still elevated in the last sample analyzed. Therefore, the use of 1 -CPG improves the retrospectivity of the detection of $\mathrm{T}$ cypionate misuse.

According to our data, the detection of urinary $1-C P G$ might be a suitable approach for the screening of T cypionate misuse.

However, the approach also shows limitations. The first one is the fact that other drugs are commercialized as cypionate esters and a similar pathway is expected to be present. Therefore, the urinary detection of $1-C P G$ is not specific of $\mathrm{T}$ cypionate misuse and its detection might be only useful as a screening strategy. A subsequent confirmation process via the currently applied gas chromatography combustion isotope ratio mass spectrometry (GCC-IRMS) procedures is compulsory. This situation is comparable with the current strategy based on GC-MS(/MS) quantification of some EAAS for screening and ulterior confirmation by GC-C-IRMS. On the other hand, T is also commercialized as other esters, like undecanoate, decaoate, isocaproate, phenylpropionate, propionate or enanthate and the approach will be not suitable to detect them. Despite some limitations, untargeted metabolomics appears as a suitable tool for the in-depth study of potential specific markers for other $T$ preparations. The approach presented in this work is innovative and opens new possibilities in the field of doping control analysis. It might complement the current screening for $\mathrm{T}$ misuse or the direct detection of $\mathrm{T}$ esters which had been proposed long ago as a way to screen for $\mathrm{T}$ abuse $\mathrm{e}^{33,34}$.

\section{CONCLUSIONS}

The usefulness of untargeted metabolomics for doping control analysis has been evaluated. The selection of an adequate procedure, that is, sample treatment, and analytical and data-treatment parameters, is of great importance in an untargeted strategy like that applied in this work. A key aspect of sample treatment is the absence of preconcentration and clean-up steps, which allows for the preservation of all analytes present in the sample. However, alternative markers at low concentration levels might be underestimated using this approach and they might be discovered only after previous preconcentration of the samples.

Urine samples collected before and after $\mathrm{T}$ administration were correctly separated by multivariate methods, giving as a result the same marker of $\mathrm{T}$ misuse using two HRMS analyzers. Both instruments seemed equally efficient for untargeted metabolomics and both were suitable for searching unknown compounds in the doping control field. These results evidenced the robustness of the methodology applied in the present work.

The strategy followed included the whole set of samples from all volunteers together and considered samples collected up to 9 days after $\mathrm{T}$ cypionate administration within the same group (Treated). Thus, only those markers which are not affected by individual metabolism and which were still detectable after long periods are picked out. The satisfactory results of this study open novel alternatives in the data treatment for the discovery of new markers. On one hand, the comparison of samples of a single individual, might lead to the discovery of new markers to be included in the ABP. On the other hand, a comparison between samples collected before and just after administration would also reveal markers for shortterm administration. Additionally, it is worth to notice that the application of a similar approach to samples collected after $\mathrm{T}$ administration in other forms (gel, oral) might reveal the presence of additional and suitable markers for the detection of this misuse.

This study confirms the suitability of state-of-the-art MS instrumentation for the development of untargeted metabolomics in doping control analysis. The developed approach allows for the detection of possible markers with the common bottleneck of the structure identification, a task that is facilitated by performing an in-depth study of the MS(/MS) fragmentation of the compound. Even so, there are still some challenges before the marker is ready to routine use. The most important is related with the specificity of the identified substance as marker for the doping agent misuse. The concentration of the ideal marker should vary after the administration of the doping agent irrespective of the administration form whereas it should remain constant under other hypothetical situations (including the administration of nonprohibited substances). More research is required to demonstrate the usefulness of the marker. Then, it might be added into currently screening methods in order to minimize the resources used by the laboratories. The im- 
plementation of a new marker for doping control analysis implies a long way in which untargeted metabolomics might be seen as the first step.

\section{ACKNOWLEDGEMENTS}

The authors acknowledge the financial support of the Ministry of Education and Science, Spain (project DEP2011-28573-Co2-01/o2) and WADA (project 14A29OP). The authors from University Jaume I also acknowledge the support from Generalitat Valenciana (Research Group of Excellence Prometeo/2009/o54; PrometeoII/2014/o23; ISIC EnviFood 2012/016).

M. Raro is also grateful to the Ministry of Economy and Competitiveness of Spain for her predoctoral grant and for the financial support for the research stay in Belgium. Spanish Health National System is acknowledged for O. J. Pozo contract (MS10/oo576).

\section{REFERENCES}

(1) Haring R. J Endocrinol. 2012, 215, 3-16.

(2) Moco S.; Bino R. J.; De Vos R. C. H.; Vervoort J. TRAC-Trends Anal Chem. 2007, 26, 855-865.

(3) Díaz R.; Pozo O. J.; Sancho J. V.; Hernández F. Food Chem. 2014, 157, 84-93.

(4) Rijk J. C. W.; Lommen A.; Essers M. L.; Groot M. J.; Van Hende J. M.; Doeswijk T. G.; Nielen M. W. F. Anal Chem. 2009, 81, 6879-6888.

(5) Roux A.; Xu Y.; Heilier J-F.; Olivier M-F.; Ezan E.; Tabet J-C.; Junot C. Anal Chem. 2012, 84, 6429-6437.

(6) Cevallos-Cevallos J. M.; Reyes-de-Corcuera J. I.; Etxeberria E.; Danyluk M. D.; Rodrick G. E. TRAC-Trends Anal Chem. 2009, 20, 557-566.

(7) Glauser G.; Veyrat N.; Rochat B.; Wolfender J-L.; Turlings T. C. J. J Chromatogr A. 2013, 1292, 151-159.

(8) Mamas M.; Dunn W. B.; Neyses L., Goodacre R. Arch Toxicol. 2011, 85, 5-17.

(9) Armitage E. G.; Rupérez F. J.; Barbas C. TRACTrends Anal Chem. 2013, 52, 61-73.

(10) Kiss A.; Jacquet A-L.; Paisse O.; Flament-Waton MM.; de Ceaurriz J.; Bordes C.; Gauvrit J-Y.; Lantéri P.; Cren-Olivé C. Talanta. 2011, 83, 1769-1773.

(11) Reichel C. Forensic Sci Int. 2011, 213, 20-34.

(12) Boccard J.; Badoud F.; Jan N.; Nicoli R.; Schweizer C.; Pralong F.; Veuthey J-L.; Baume N.; Rudaz S.; Saugy M. Bioanalysis. 2014, 6:19, 2525-2536.

(13) World Anti-Doping Agency. 2013 Antidoping testing figures-Sport Report. Available from: https://wadamain-prod.s3.amazonaws.com/resources/files/WADA2013-Anti-Doping-Testing-Figures-LABORATORYREPORT.pdf. Last accesed 5.3.2015.

(14) Donike M.; Bärwald K-R.; Klostermann K.; Schänzer W.; Zimmermann J. Nachweis von exogem testosterone. Editors: Heck H., Hollmann W., Leisen H., Rots R. Testosterone in sport: leistung und gesundheit 1983, 293300.
(15) Starcevic B.; Butch A. Clin Chem. 2008, 54:12, 19451947.

(16) Kicman A. T. Brit J Pharmacol. 20o8, 154:3, 502-521.

(17) Robinson N.; Saugy M.; Vernec A.; Sottas P-E. Clin Chem. 2011, 57:6, 830-832.

(18) Fabregat A.; Pozo O. J.; Marcos J.; Segura J.; Ventura R. Anal Chem. 2013, 85:10, 5005-5014.

(19) Fabregat A.; Kotronoulas A.; Marcos J.; Joglar J.; Alfonso I.; Segura J.; Ventura R.; Pozo O. J. Steroids. 2013, 78:3, 327-336.

(20) Van Renterghem P.; Van Eenoo P.; Sottas P. E.; Saugy M.; Delbeke F. Clin Endocrinol. 2011, 75:1, 134-140.

(21) Van Renterghem P.; Sottas P. E.; Saugy M.; Van Eenoo P. Anal Chim Acta. 2013, 768, 41-48.

(22) Kiss A.; Lucio M.; Fildier A.; Buisson C.; AchmittKopplin P.; Cren-Olivé C. Plos One. (2013) 8:9, 1-13.

(23) Scripps centre for Metabolomics: XCMS Online. Available from: https://xcmsonline.scripps.edu/ Last accessed 13.6.2014.

(24) Schmidt M. T.; Handschuh L.; Zyprych J.; Szabelska A.; Olejnik-Schmidt A. K.; Siatkowski I.; Figlerowicz M. Acta Biochim Pol. 2011, 58, 573-580.

(25) Fabregat A.; Marcos J.; Garrostas L.; Segura J.; Pozo O.J.; Ventura R. J Steroid Biochem Mol Biol. 2014, 139, 192200

(26) Deventer K.; Pozo O. J.; Verstraete A. G.; Van Eenoo P. TRAC-Trends Anal Chem. 2014, 55, 1-13.

(27) Naz S.; Vallejo M.; García A.; C. Barbas. J Chromatogr A. 2014, 1353, 99-105.

(28) Dunn W. B.; Wilson I. D; Nicholls A. W.; Broadhurst D. Bioanalysis. 2012, 18, 2249-2264.

(29) Boccard J.; Rutledge D. N. Anal Chim Acta. 2013, 769, 30-39.

(30) Schulz H., Kunau W-H. Trends Biochem Sci. 1987, 12, 403-406.

(31) Gregus Z.; Fekete T.; Halászi E.; Klaassen C. D. Drug Metab Dispos. 1996, 24, 682-688.

(32) Smith H. G.; Smith W. R. D.; Jepson J. B.; Sorenson K. Biochem Pharmacol. 1970, 19, 1689-1693.

(33) Shackleton C.H.; Chuang H., Kim J., de la Torre X.; Segura J. Steroids. 1997, 62, 523-9.

(34) Peng S.H.; Segura J.; Farre M.; González J.C.; de la Torre X. Steroids. 2002, 67, 39-50.

\section{FIGURES}

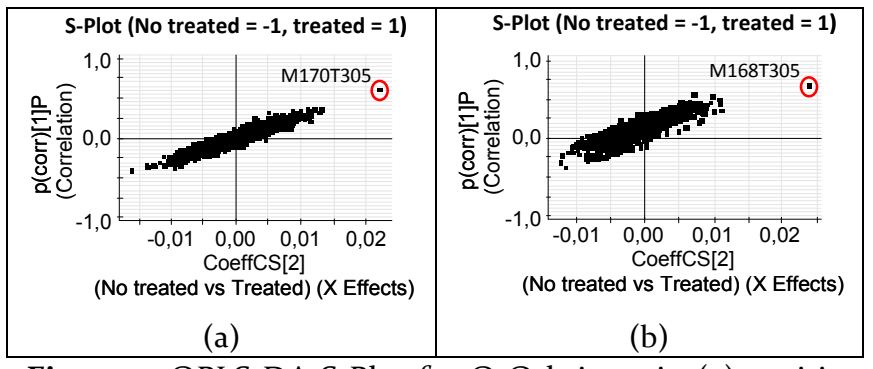

Figure 1. OPLS-DA S-Plot for Q Orbritrap in (a) positive ionization mode and (b) negative ionization mode. Signi- 
ficant markers $(\mathrm{m} / \mathrm{z}$ and $\mathrm{RT})$ are highlighted. See more information in Table 1.

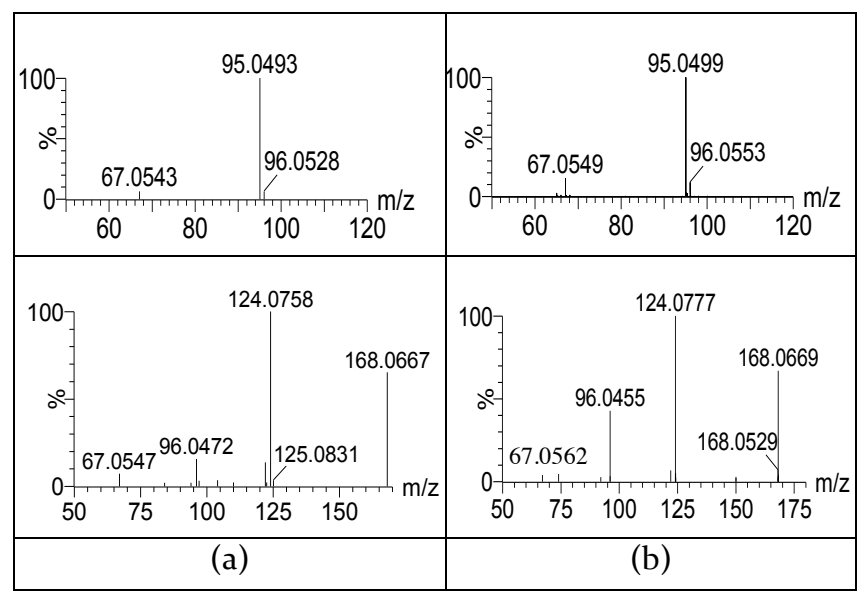

Figure 2. Product ion spectra in both positive (top) and negative (bottom) ionization mode for (a) urinary marker M170T295 and (b) synthesized 1-CPG

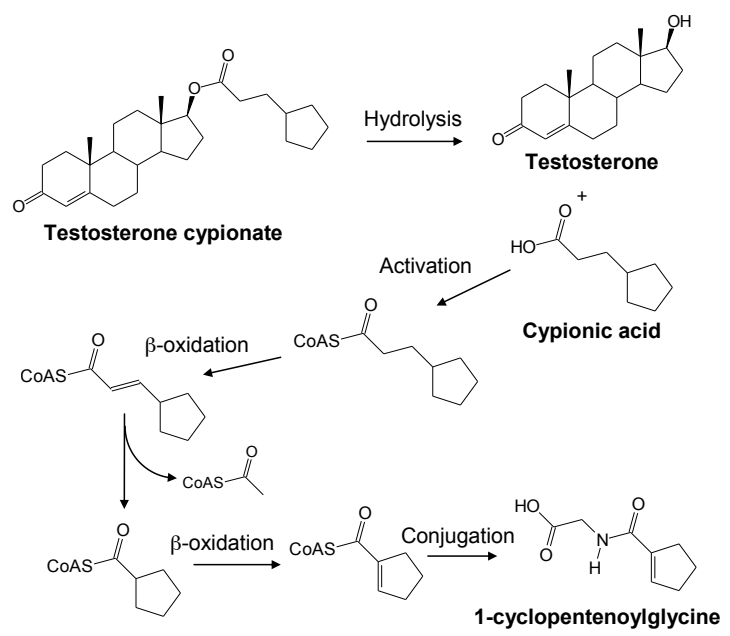

Figure 3. Proposed metabolic pathway involved in the urinary occurrence of 1 -CPG after testosterone cypionate injection

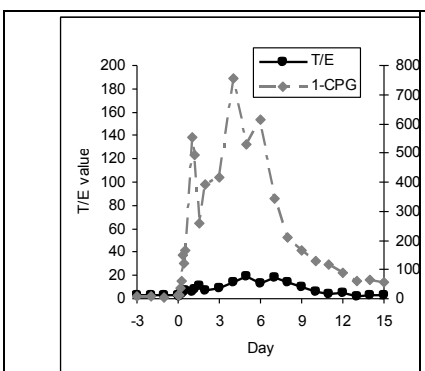

(a)

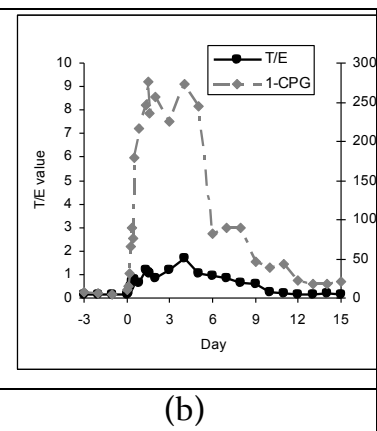

(b)
Figure 4. Comparison of the excretion profile of 1-CPG compared with $\mathrm{T} / \mathrm{E}$ in (a) volunteer with basal $\mathrm{T} / \mathrm{E}=\mathbf{2 . 9}$ and (b) volunteer with basal $\mathrm{T} / \mathrm{E}=0.16$.
Table 1. Best features obtained from OPLS-DA S-Plot, in QTOF and Q Orbitrap in both ionization modes. *selected markers for study. M stands for $\mathrm{m} / \mathrm{z}$ and $\mathrm{T}$ for retention time.

\begin{tabular}{|c|c|c|c|c|c|}
\hline & \multicolumn{2}{|c|}{$\begin{array}{c}\text { Increase after } \mathrm{T} \\
\text { administration (right) }\end{array}$} & \multicolumn{2}{|c|}{$\begin{array}{c}\text { Decrease after } T \\
\text { administration (left) }\end{array}$} \\
\hline & & Marker & $\mathrm{p}$ (corr) & Marker & $\mathrm{p}($ corr $)$ \\
\hline \multirow{10}{*}{ ○, } & \multirow{5}{*}{$\sum_{0}^{n}$} & M95T295* & 0,64951 & $\mathrm{M}_{259} \mathrm{~T}_{555}$ & $-0,43191$ \\
\hline & & M170T295* & 0,62215 & $\mathrm{M}_{228 \mathrm{~T}} 456$ & $-0,39339$ \\
\hline & & M951T542_1 & 0,4789 & $\mathrm{M}_{511} \mathrm{~T}_{554}$ & $-0,39040$ \\
\hline & & $\mathrm{M}_{994} \mathrm{~T}_{542}$ & 0,47680 & $\mathrm{M}_{227} \mathrm{~T}_{456}$ & $-0,38987$ \\
\hline & & M951T542_2 & 0,47375 & $\mathrm{M} 283 \mathrm{~T} 274$ & $-0,38928$ \\
\hline & \multirow{5}{*}{ 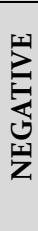 } & $\mathrm{M}_{249 \mathrm{~T}_{3} 80}$ & 0,78888 & M192T217 & $-0,42053$ \\
\hline & & M168Т295 & 0,77079 & $\mathrm{M}_{422 \mathrm{~T}} 355$ & $-0,36789$ \\
\hline & & M369T381_1 & 0,74499 & $\mathrm{M}_{286 \mathrm{~T}} 422$ & $-0,36677$ \\
\hline & & $\mathrm{M}_{367 \mathrm{~T}_{3} 81}$ & 0,53850 & $\mathrm{M}_{457} \mathrm{~T}_{544}$ & $-0,35284$ \\
\hline & & $\mathrm{M}_{371} \mathrm{~T}_{381}$ & 0,38594 & $\mathrm{M}_{451} \mathrm{~T}_{448}$ & $-0,34879$ \\
\hline \multirow{10}{*}{$\begin{array}{l}\text { है } \\
\stackrel{\Xi}{0} \\
\text { है } \\
0 \\
0\end{array}$} & \multirow{5}{*}{$\sum^{2}$} & $\mathrm{M}_{170 T} 305^{*}$ & 0,60247 & $\mathrm{M}_{26} \mathrm{~T}_{42}$ & $-0,40982$ \\
\hline & & $\mathrm{M}_{333 \mathrm{~T} 230}$ & 0,36836 & $\mathrm{M}_{127} \mathrm{~T}_{59}$ & $-0,38174$ \\
\hline & & $\mathrm{M}_{114} \mathrm{~T} 238$ & 0,35049 & $\mathrm{M}_{132} \mathrm{~T}_{73}$ & $-0,35674$ \\
\hline & & $\mathrm{M}_{183} \mathrm{~T}_{31}$ & 0,34885 & M138T107 & $-0,35498$ \\
\hline & & M85T39 & 0,34856 & $\mathrm{M}_{328 \mathrm{~T}_{358}}$ & $-0,35203$ \\
\hline & \multirow{5}{*}{ 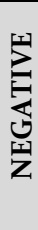 } & M168T305* & 0,67447 & $\mathrm{M} 123 \mathrm{~T} 287$ & $-0,38195$ \\
\hline & & M165T23 & 0,41701 & $\mathrm{M}_{151 \mathrm{~T}} 35$ & $-0,36366$ \\
\hline & & $\mathrm{M}_{501} \mathrm{~T}_{563}$ & 0,39021 & $\mathrm{M}_{279} \mathrm{~T}_{575}$ & $-0,35547$ \\
\hline & & M215T65 & 0,35798 & $\mathrm{M}_{229} \mathrm{~T}_{510}$ & $-0,33049$ \\
\hline & & $\mathrm{M}_{373} \mathrm{~T}_{517}$ & 0,35584 & $\mathrm{M}_{179} \mathrm{~T}_{463}$ & $-0,33011$ \\
\hline
\end{tabular}

Table 2. Full scan and product ion scan information of the selected marker for QTOF

\begin{tabular}{|c|c|c|c|c|c|}
\hline \multirow{4}{*}{ స్ } & Ionization & Marker & $\begin{array}{c}\text { Accurate } \\
\text { mass }\end{array}$ & $\begin{array}{l}\text { Error } \\
\text { (ppm) }\end{array}$ & Formula \\
\hline & ESI+ & M17oT295 & 170.0817 & o & $\mathrm{C}_{8} \mathrm{H}_{12} \mathrm{NO}_{3}$ \\
\hline & ESI- & M168T295 & 168.0657 & -2.4 & $\mathrm{C}_{8} \mathrm{H}_{10} \mathrm{NO}_{3}$ \\
\hline & Ionization & $\begin{array}{l}\text { Marker } \\
(\mathrm{CE} \text { eV) }\end{array}$ & $\begin{array}{c}\text { Product } \\
\text { ion } \\
(\mathrm{m} / \mathrm{z})\end{array}$ & $\begin{array}{l}\text { Error } \\
\text { (ppm) }\end{array}$ & Formula \\
\hline \multirow{5}{*}{ 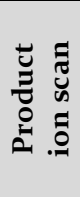 } & \multirow{2}{*}{ ESI+ } & \multirow{2}{*}{$\begin{array}{l}\text { M170T295 } \\
(20)\end{array}$} & 95.0493 & -4.2 & $\mathrm{C}_{6} \mathrm{H}_{7} \mathrm{O}$ \\
\hline & & & 67.0543 & -4.5 & $\mathrm{C}_{5} \mathrm{H}_{7}$ \\
\hline & \multirow{3}{*}{ ESI- } & \multirow{3}{*}{$\begin{array}{l}\text { M168T295 } \\
\text { (20) }\end{array}$} & 124.0758 & -3.2 & $\mathrm{C}_{7} \mathrm{H}_{10} \mathrm{NO}$ \\
\hline & & & 96.0472 & 23.9 & $\mathrm{C}_{5} \mathrm{H}_{6} \mathrm{NO}$ \\
\hline & & & 67.0547 & -1.5 & $\mathrm{C}_{5} \mathrm{H}_{7}$ \\
\hline
\end{tabular}

*Corresponding author: Óscar J Pozo e-mail: opozo@imim.es

Bioanalysis Research Group,

IMIM, Hospital del Mar Medical Research Institute, Doctor Aiguader 88, o8003 Barcelona, Spain Phone: 0034-933160472, Fax: 0034-933160499 


$$
x=
$$




\section{List of authors:}

Montse Raro ${ }^{\mathrm{a}}$, María Ibáñez ${ }^{\mathrm{a}}$, Rubén Gil ${ }^{\mathrm{a}}$, Andreu Fabregat ${ }^{\mathrm{b}}$, Eva Tudela $^{\mathrm{c}}$, Koen Deventer ${ }^{\mathrm{c}}$, Rosa Ventura, ${ }^{\mathrm{b}, \mathrm{d}}$, Jordi Segura, ${ }^{\mathrm{b}, \mathrm{d}}$, Josep Marcos ${ }^{\mathrm{b}, \mathrm{d}}$, Aristotelis Kotronoulas ${ }^{\mathrm{b}, \mathrm{e}}$, Jesús Joglar ${ }^{\mathrm{e}}$, Magi Farré, Sheng Yang ${ }^{\mathrm{g}}$, Yanyi Xing ${ }^{\mathrm{g}}$, Peter Van Eenoo ${ }^{\mathrm{f}}$, Elena Pitarch ${ }^{\mathrm{a}}$, Félix Hernández $^{\mathrm{a}}$, Juan Vicente Sancho ${ }^{\mathrm{a}}$, Óscar J. Pozo ${ }^{\mathrm{b} *}$

${ }^{a}$ Research Institute for Pesticide and Water, University Jaume I, Av. Sos Baynat S/N, 12071 Castellón, Spain

${ }^{\mathrm{b}}$ Bioanalysis Research Group. IMIM, Hospital del Mar, Dr. Aiguader 88, 08003 Barcelona, Spain

${ }^{\mathrm{c}}$ DoCoLab, Ghent University, Technologiepark 30, 9052, Zwijnaarde, Belgium

${ }^{\mathrm{d}}$ Department of Experimental and Health Sciences, Universitat Pompeu Fabra, Doctor Aiguader 88, 08003 Barcelona, Spain

${ }^{\mathrm{e}}$ Department of Biological Chemistry and Molecular Modelling, Institute of Advanced Chemistry of Catalonia, Spanish Council for Scientific Research (IQAC-CSIC), Jordi Girona 18-26, 08034 Barcelona, Spain

${ }^{\mathrm{f}}$ Human Pharmacology and Neurosciences Research Group, IMIM, Clinical Pharmacology Unit, Hospital Universitari Germnans Trias I Pujol-IGTP and Universitat Autònoma de Barcelona, Doctor Aiguader 88, 08003 Barcelona, Spain

${ }^{g}$ National Anti-Doping Laboratory China Anti-Doping Agency, 1, An Ding Road, Beijing, 100029, China

\section{Title of the article:}

Untargeted metabolomics in doping control: detection of new markers of testosterone misuse by ultra-high performance liquid chromatography coupled to high resolution mass spectrometry

\footnotetext{
Abstract

The workflow used is a critical step for the development of untargeted metabolomic approaches. Figure S-1 shows the strategy applied in the present study. Additionally, acquired data should be normalized before data processing. Results of normalization are shown in Figure S-2. In the presented strategy, potential markers were selected after application of OPLS-DA. Before this application, both PCA and PLS-DA were tested in order to evaluate the behavior of the QCs. PCA plots for both instruments are shown in Figure S-3 and PLS-DA obtained are shown in Figure S-4. The next step was the generation of the S-Plots of the orthogonal PLS-DA (OPLS-DA); in Figure S-5, S-Plots for QTOF-MS are shown. In order to evaluate if features from S-Plot are good candidates for elucidation, Variable Trend Plots like the ones shown in Figure S-6, were studied. Additionally, some experimental parameters are included in this document.
} 


\section{Table of contents:}

Experimental S1. QTOF calibration and lock mass............................ Page S-3

Experimental S2. Purification of synthesized 1-CPG ......................... Page S-3

Experimental S3. Determination of 1-CPG by LC-MS/MS ........................Page S-3

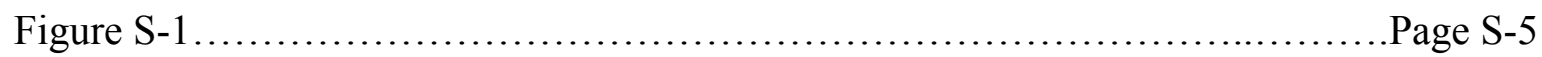

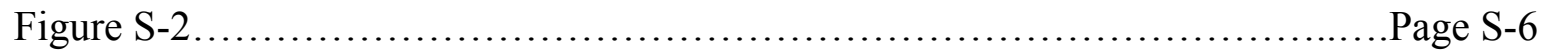

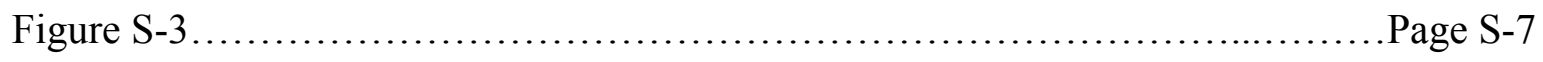

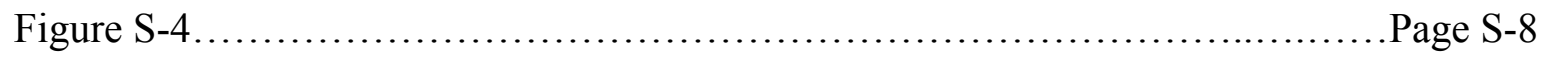

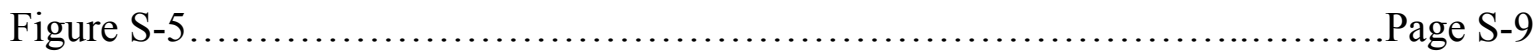

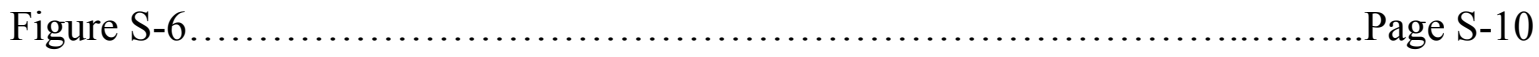

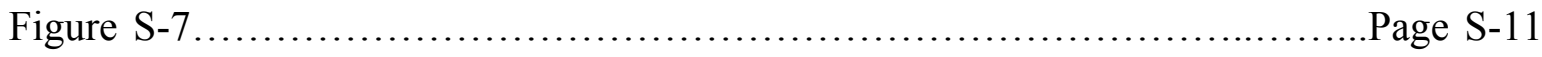




\section{EXPERIMENTAL}

\section{S1. QTOF calibration and lock mass}

Calibration of the mass-axis from $\mathrm{m} / \mathrm{z} 50$ to 1000 was conducted daily with a $1: 1$ mixture of $0.05 \mathrm{M} \mathrm{NaOH}: 5 \%(\mathrm{v} / \mathrm{v}) \mathrm{HCOOH}$ diluted (1:25) with water/acetonitrile (ACN) $(20: 80 \mathrm{v} / \mathrm{v})$.

For automated accurate mass measurement, the lock-spray probe was employed, using as lockmass Leucine-Enkephalin (10 mg/L) in ACN:water (50:50) and 0.1\% $\mathrm{HCOOH}$, pumped at $20 \mu \mathrm{L} / \mathrm{min}$ through the lock-spray needle. $[\mathrm{M}+\mathrm{H}]+(\mathrm{m} / \mathrm{z} 556.2771)$ and $[\mathrm{M}-\mathrm{H}]-(\mathrm{m} / \mathrm{z} 554.2615)$, were used for recalibrating the mass axis in positive and negative ionization modes respectively.

\section{S2. Purification of synthesized 1-CPG}

For the purification of 1-CPG, the reaction's solution was directly injected to a semi-preparative HPLC (Waters Prep LC 4000 system) equipped with an Atlantis ${ }^{\circledR}$ dC18 OBDTM column $(5 \mu \mathrm{m}, 19 \mathrm{~mm} \times 150 \mathrm{~mm})$. The mobile phases used were $(\mathrm{A}): 0.01 \%$ trifluoroacetic acid (TFA) in $\mathrm{H} 2 \mathrm{O}$ and (B): 20:80:0.01, v/v/v ACN-H2O-TFA and the selected gradient changed as follow: $0 \%$ B for $5 \mathrm{~min}, 0 \%$ to $35 \%$ B in $35 \mathrm{~min}$.

\section{S3. Determination of 1-CPG by LC-MS/MS}

\section{S3.1. Instrumentation}

Chromatographic separation was performed by an Acquity UPLC instrument (Waters Associates, Milford, Massachusetts, USA). An Acquity UPLC ${ }^{\circledR}$ BEH C18 $1.7 \mu \mathrm{m}$ 2.1x100 mm column (Waters Associates) was used for the separation. Water (A) and methanol (B) both with $0.01 \% \mathrm{HCOOH}$ and $1 \mathrm{mM}$ ammonium formate were selected as 
mobile phase solvents. During the gradient program used, the percentage of organic solvent changed as following: $0 \mathrm{~min}, 1 \%$; 9 min, 30\%; $10 \min 95 \%$; $11 \mathrm{~min} ; 95 \%$; $12 \min 1 \%$; 14 $\min ; 1 \%$. The injection volume was $10 \mu \mathrm{L}$ and the flow rate $0.3 \mathrm{~mL} / \mathrm{min}$.

The detection was performed with a triple quadrupole (Quattro Premier XE, Waters) mass spectrometer equipped with an orthogonal Z-spray-electrospray ionization source (ESI). The desolvation gas flow was set to approximately $1200 \mathrm{~L} / \mathrm{h}$ and the cone gas flow to $50 \mathrm{~L} / \mathrm{h}$. Nitrogen was used as drying and nebulising gas. A cone voltage of $15 \mathrm{~V}$ and a capillary voltage of $3.0 \mathrm{kV}$ were used in positive ionization mode. The nitrogen desolvation temperature was set to $450{ }^{\circ} \mathrm{C}$ and the source temperature to $120^{\circ} \mathrm{C}$. The monitoring and quantification of 1-CPG was performed using the transition $170 \rightarrow 95$ with a collision energy of $10 \mathrm{eV}$.

\section{S3.2. Sample preparation}

A volume of $100 \mu \mathrm{L}$ of urine were mixed with the same volume of acetic acid 1M. $10 \mu \mathrm{L}$ of the diluted sample were directly injected into the LC-MS/MS system. 


\section{FIGURE S-1}

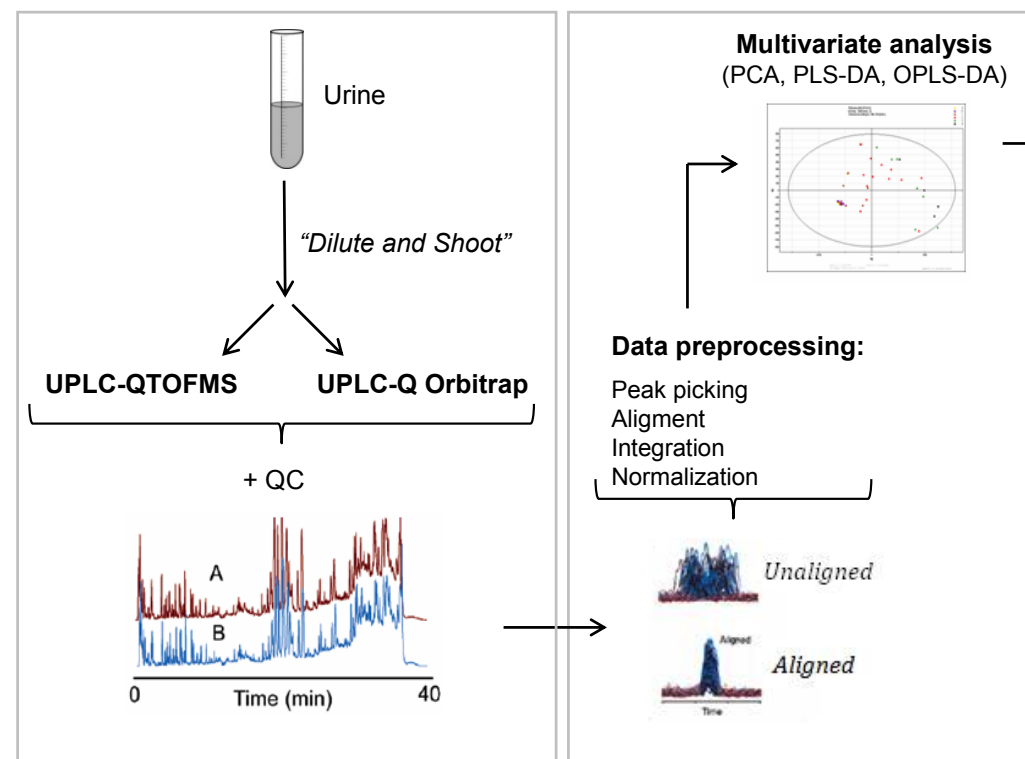

a) Analytical procedure

b) Metabolomic approach

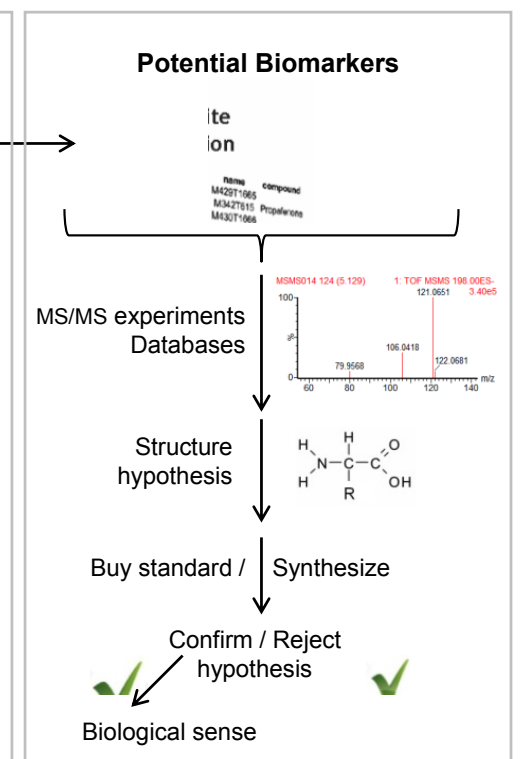

c) Marker(s) elucidation

Simplified workflow of the employed strategy, schematized in three blocks: a) the analytical procedure applied, b) the metabolomic approach followed and c) the work carried out for the structural identification of the potential markers. 
FIGURE S-2

(a)

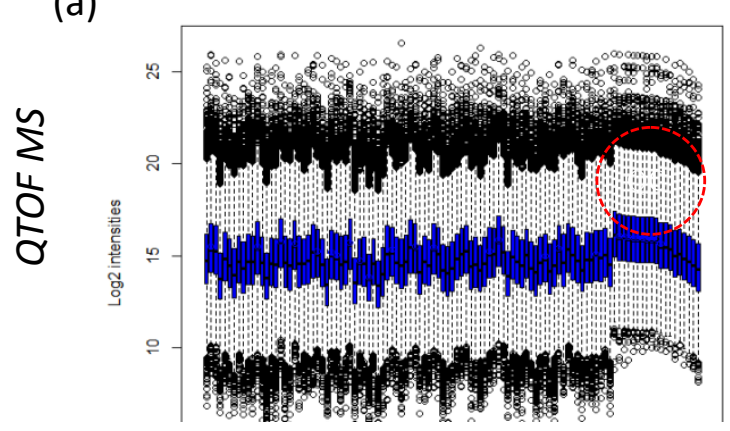

(c)

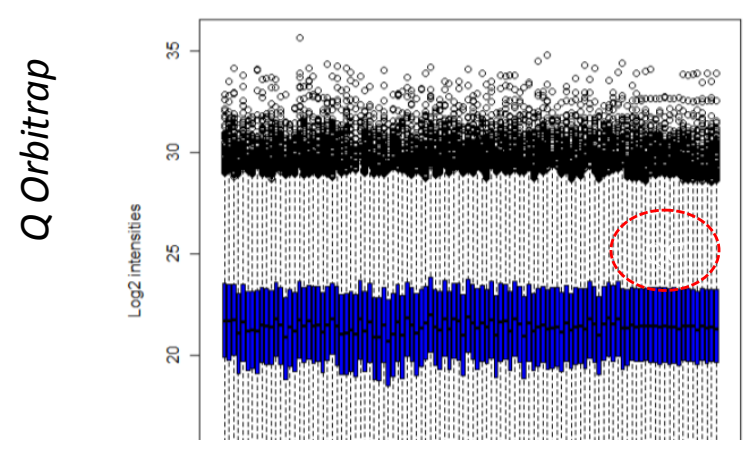

(b)

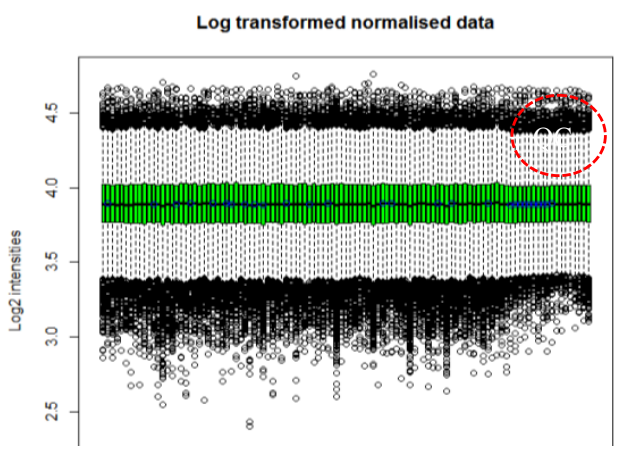

(d)

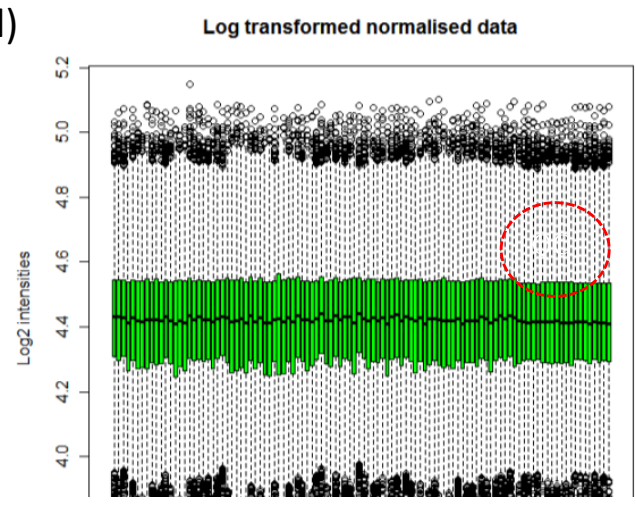

Box plots of the $\log _{2}$ of the intensities of the components of the different samples in positive mode a) QTOF MS data before normalization (blue), b) QTOF MS data after normalization (green), c) Q Orbitrap MS data before normalization (blue), d) Q Orbitrap MS data after normalization (green). 


\section{FIGURE S-3}
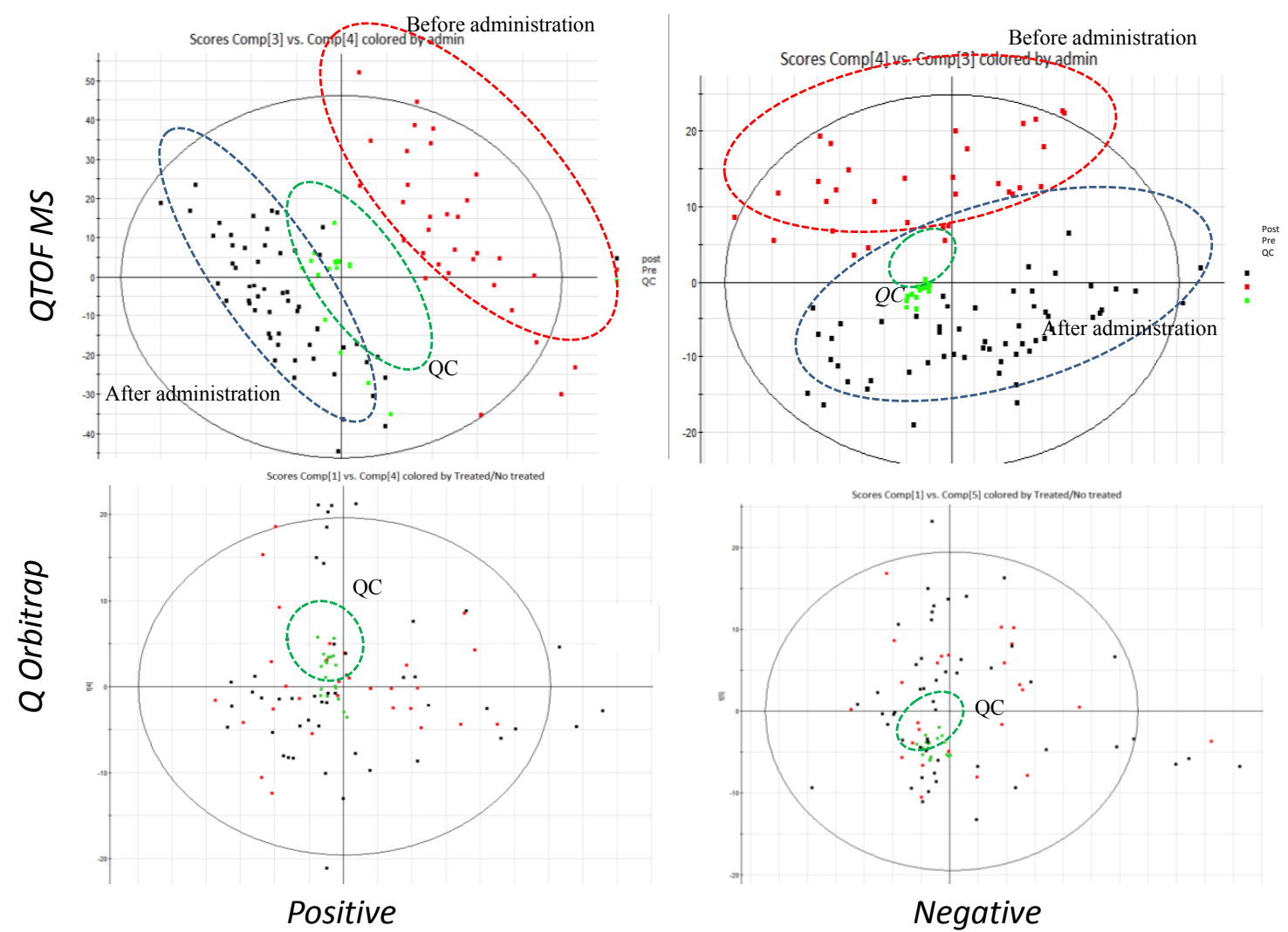

Principal Component Analysis (PCA) score plots from QTOF and Q Orbitrap MS in positive and negative ionization modes. Groups of samples before administration are highlighted in a red circle, samples after administration in blue and QC in green. 


\section{FIGURE S-4}
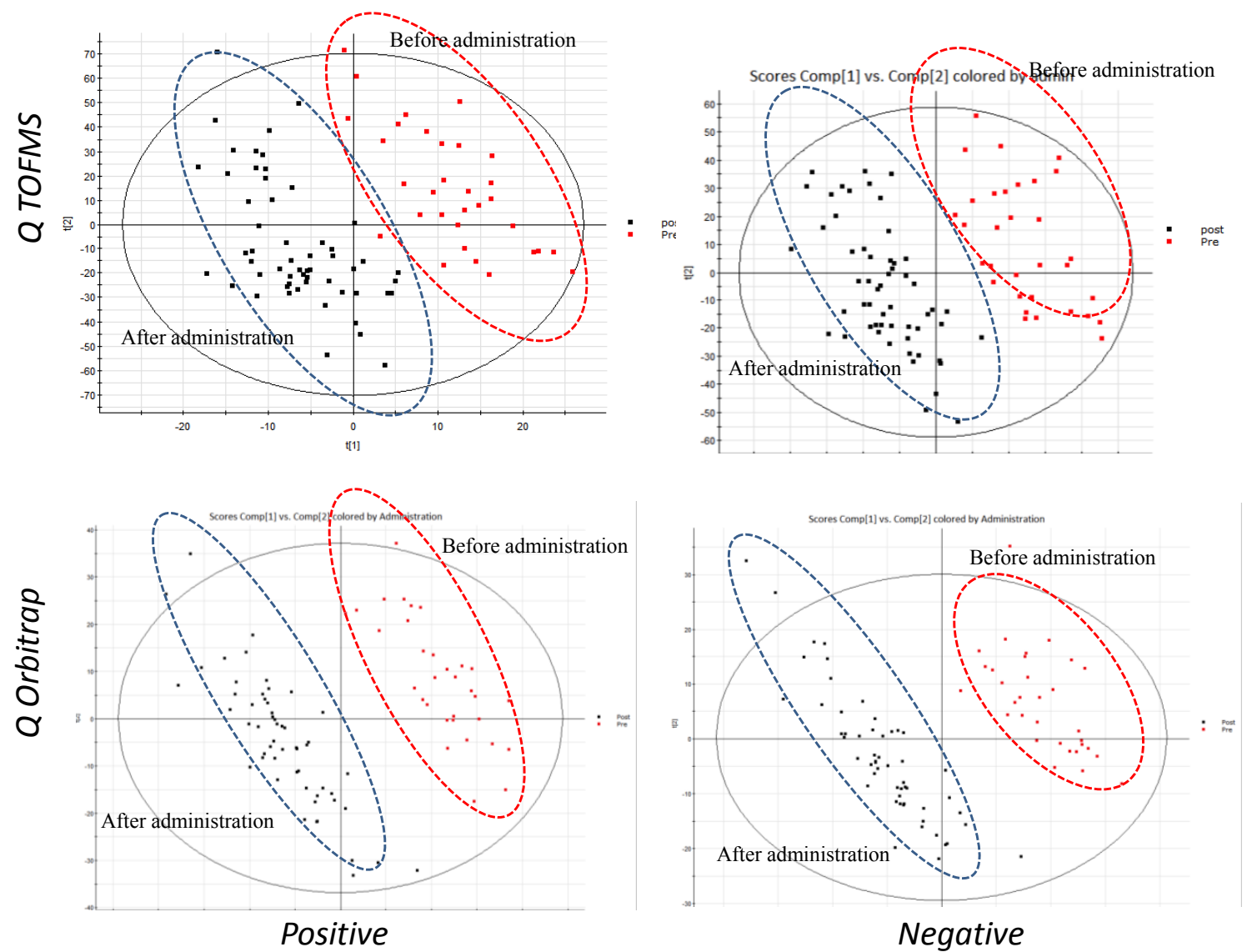

Partial Least Square Discriminant Analysis (PLS-DA) score plots from QTOF and Q Orbitrap MS in positive and negative ionization modes. Groups of samples before administration are highlighted in a red circle and samples after administration in blue. 
FIGURE S-5

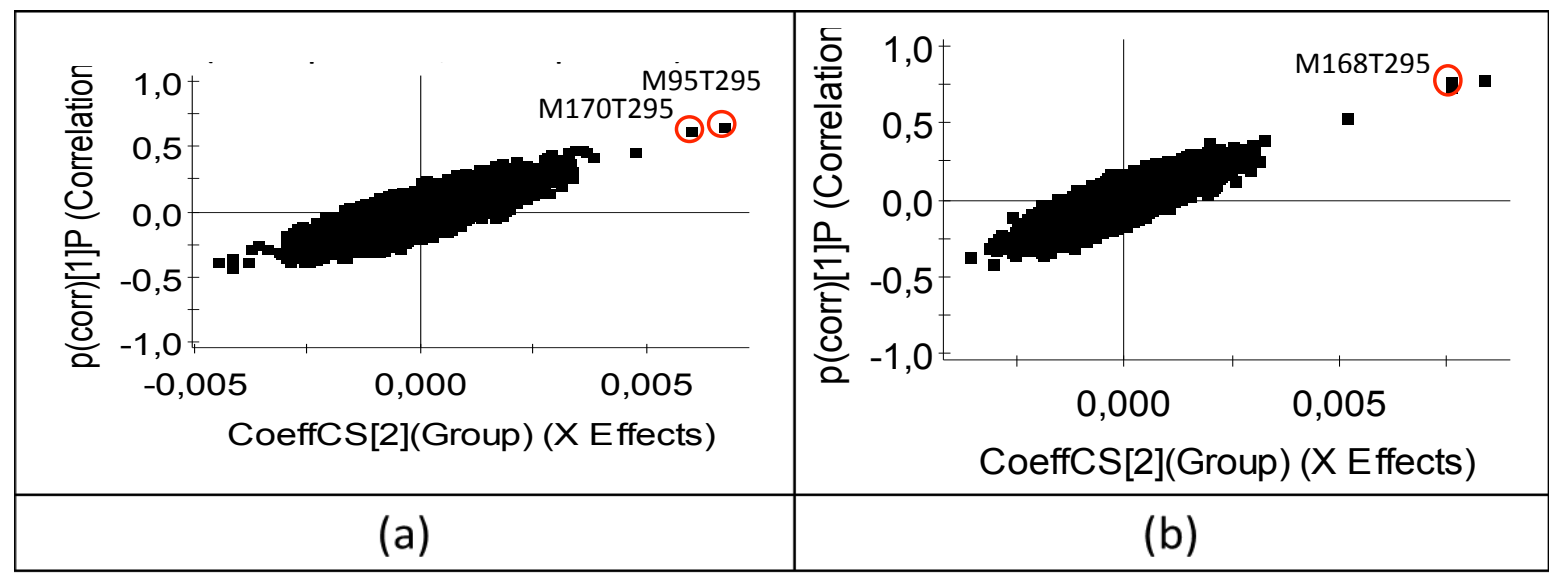

OPLS-DA S-Plot for QTOF MS in (a) positive ionization mode and (b) negative ionization mode. Significant markers $(\mathrm{m} / \mathrm{z}$ and RT) are highlighted. 


\section{FIGURE S-6}

(a)

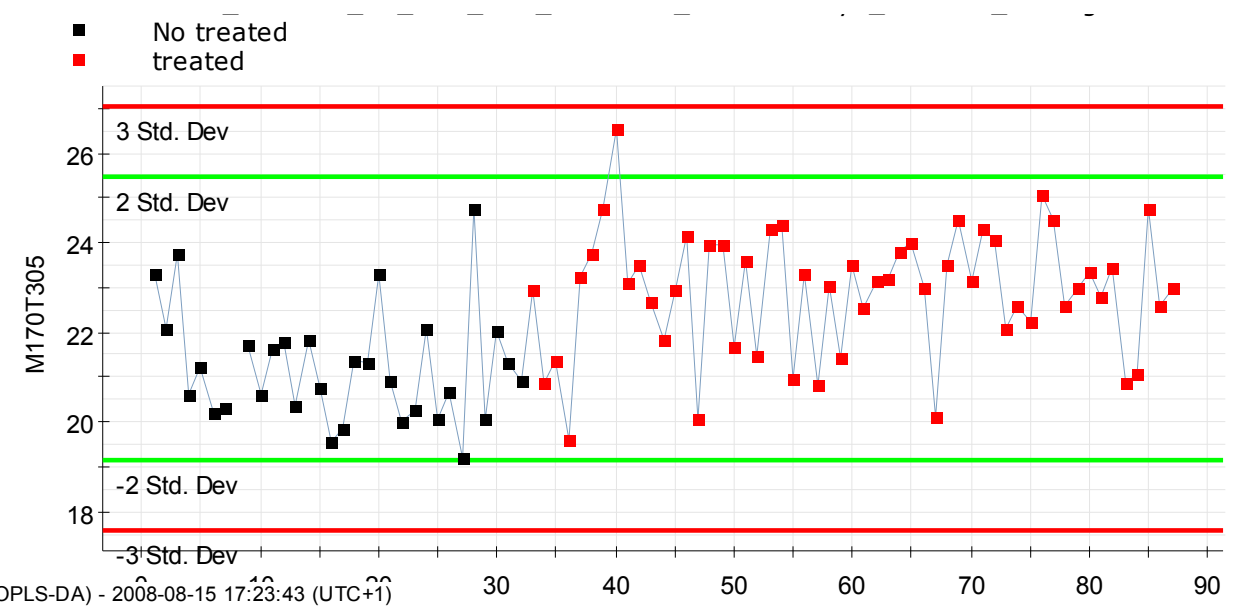

(b)

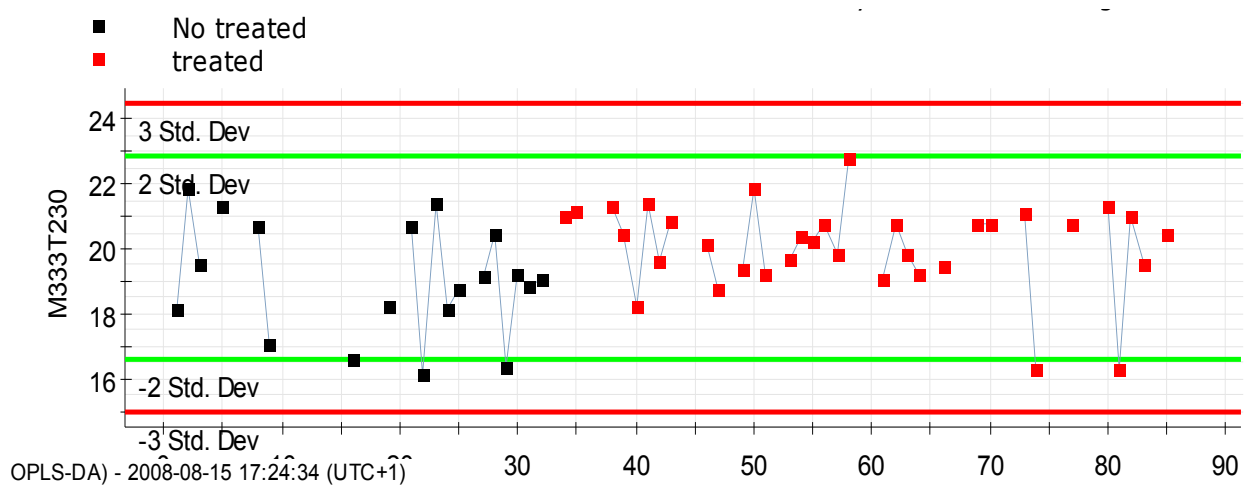

Variable trend plots from Q Orbitrap data. Features a) M170T305 and b) M333T230. Samples before administration are represented in black points whereas samples after administration are represented in red. 


\section{FIGURE S-7}

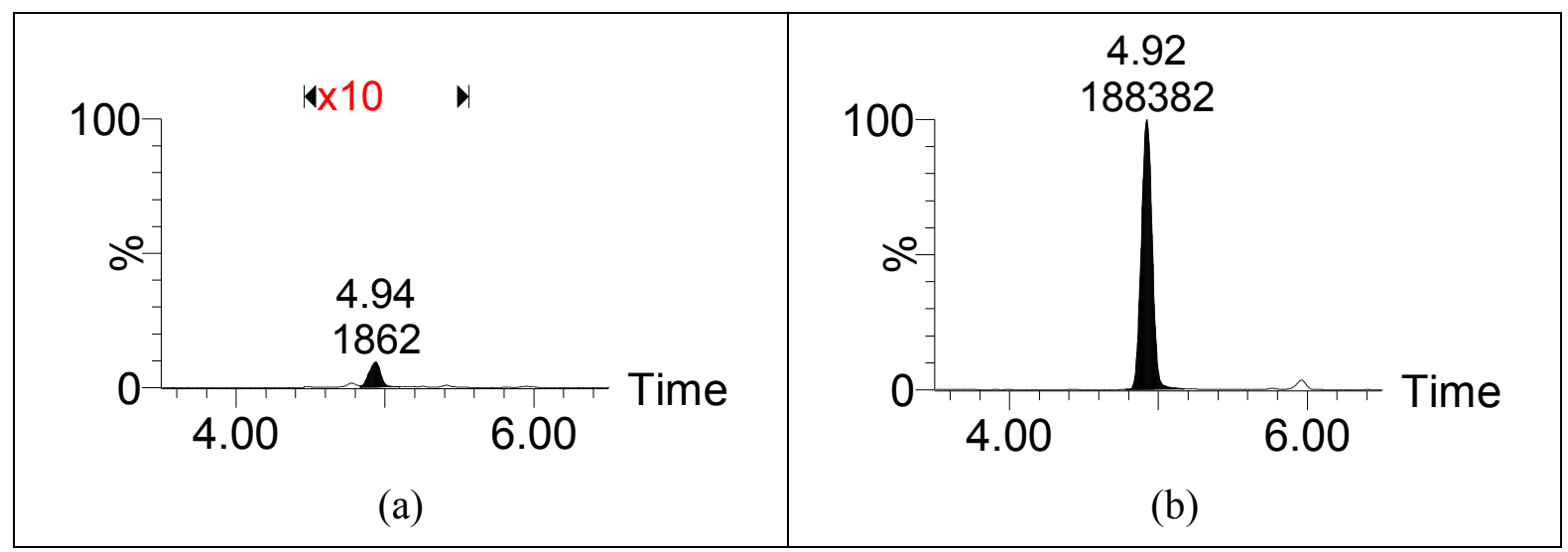

LC-MS/MS chromatograms for the determination of 1-CPG (a) sample collected 2 days before testosterone cypionate administration and (b) sample collected 8 days after testosterone cypionate administration. 